\title{
Emisiones militares pompeyanas del año 49 a.C. en Hispania
}

\author{
LUIS AMELA VALVERDE
}

\begin{abstract}
RESUMEN
En este artículo se describen las monedas acuñadas por los legados

de Pompeyo Magno en Hispania durante el año 49 a.C. (dos emisiones de denarios, RRC 446447). Se analiza los diferentes tipos iconográficos de anversos y reversos, leyendas y lugar de emisión.
\end{abstract}

\author{
ABSTRACT \\ This article describe the coins \\ minted by the legates of Pompey the \\ Great in Hispania during the year 49 \\ B.C. (two emission of denarius, RRC \\ 446-447). The different \\ iconographical types of obverse and \\ reverse, legends and mint of the \\ coins are analyzed.
}

La fase final de la República romana ve el afloramiento de numerosas emisiones provinciales. Entre éstas se destacan en particular las amonedaciones hispánicas ${ }^{1}$, efectuadas durante el conflicto entre cesarianos y pom-

1 Vid: TH. V. ButTaEY JR., "The Denarii of Cn. Pompeius Jr. and M. Minatius Sabinus", ANSMusN 9 (1960), 75-94; "The Pietas denarii of Sextus Pompey"», NC 10 (1960), 53-101. C. MiLLAN, “Aspectos hispánicos de la familia Pompeia", en Congresso internazionale di Numismatica. Vol. II. Atti (Roma, 1965), 293. 298. H. ZEHNACKER, "Liconographie pompèienne et les styles monétaires à la fin de la République Romaine", en Congresso internazionale di Numismatica. Vol. Il. Atti (Roma, 1965), 283-292. M. CAMPO, "Los denarios romano-republicanos acuñados en Hispania", ANum 3 (1973), 53-64. A. AlvaR EzouERRA, "Lucano, Farsalia VIII, 663-711 y las acuñaciones de Marco Minacio Sabino", en Actas del II Congreso andaluz de estudios clásicos, Il (Málaga, 1987), 121-128. R. MARTINI, Monetaziones bronzea romana tardo-repubblicana I. Divos Iulius di Octavianus, "assi" di Sextus Pompeius, emissioni dei prefetti di Antonius, Milano, 1988; "Note metrologiche sulle emissioni bronzee di Sextus Pompeius", GN 94-95 (1989), 23-29. L. AMELA VALVERDE, "La amonedación pompeyana en Hispania. Su utilización como medio propagandístico y como reflejo de la clientela de la gens Pompeia», Faventia 12-13 (1990-1991), 181-197; "Las monedas de bronce acuñadas por Sexto Pompeyo en Hispania", GN 113 (1994), 33-37; “Acuñaciones de denarios romano-republicanos de Pompeyo Magno en Hispania durante el año 49 a.C.", GN 134 (1999), 15-23; «Las acuñaciones romanas de Sexto Fompeyo en Hispania", AEspA 73 (2000), 105-119; "Acuñaciones de Cneo Pompeyo hijo en Hispania", Numisma 244 (2000), 7-33; "La emisión cesariana RRC 443/1 y sus imitaciones", Numisma 246 (2002), 7-37; "Sobre una supuesta variante de RRC 469/1 a y otros comentarios acerca de esta moneda", GN 151 (2003), 9-14; “Aulo Hircio en Hispania. Los (falsos) datos de la numismática», HAnt 28 (2004), en prensa; "El denario RRC 468, acuñado en Hispania", en XI Congreso Nacional de Numismática, (Zaragoza 2003), 65-70; "Emisiones de bronce pompeyanas de Hispania. Su relación con otras amonedaciones del Mediterráneo Occidental", en XIII Congreso Internacional de Numismática, en prensa.- Las emisiones pompeyanas fueron acuñadas en momentos diferentes, que corresponden a los periodos en que se ha de dividir la guerra entre Pompeyo Magno y sus hijos y César en Hispania. Más importante, reflejan la disposición de esta familia con respecto a la Península lbérica. Asi, las acuñaciones de Pompeyo Magno (RRC 446-447) muestran la estrategia que pensaba seguir en el enfrentamiento contra César, mostrando la flota de Oriente y las legiones de Occidente. Las de Cneo Pompeyo hijo representan la acogida y ayuda que recibió de las provincias hispanas (RRC 469-471), convirtiéndose la Península lbérica en el único territorio que resistió al invencible César. En cambio, las acuñaciones de Sexto Pompeyo son más reservadas (RRC 477-479), debido a las muertes de su padre y de su hermano mayor, a quienes recuerda. 
peyanos (49-44 a.C. $)^{2}$. Ambos bandos usaron este medio propagandístico, aunque si bien Pompeyo Magno debía aparecer como señor del mundo romano, sus partidarios no utilizaron los mismos procedimientos que los cesarianos, para no ir en contra de las tradiciones republicanas que decían defender, pero en su desarrollo no fueron tan hábiles como sus adversarios ${ }^{3}$.

Las monedas romanas acuñadas por la gens Pompeia en Hispania cumplen con las líneas generales trazadas por Alföldi para las acuñaciones del periodo: en el siglo I a.C. se puede observar como los antepasados de las grandes familias son desplazados en las efigies de las monedas por sus descendientes vivos, produciendo a su vez el relato de hechos contemporáneos ${ }^{4}$, como se puede evidenciar en las emisiones de Cneo Pompeyo hijo y Sexto Pompeyo ${ }^{5}$. Se trata, por tanto, de importantísimos documentos tanto sobre el desarrollo de la guerra civil en la Península Ibérica, como de la relación e la gens Pompeia con Hispania (a la que se puede considerar como una segunda patria ${ }^{6}$ ), ya que sustentó su causa por tres veces. Buena muestra de ello es la numerosa clientela pompeyana existente, bien documentada por las fuentes literarias (BAfr. 22, 4. Caes. BCiv. 2, 18, 7. Sall. Cat. 19, 5)7.

2 Sobre este conflicto en Hispania, vid: P. Prieto y Llovera, Campaña de Julio César ante Lérida, Lérida, 1952. E. GABBA, "Aspetti della lotta in Spagna di Sesto Pompeo», en Legio VII Gemina (León, 1970), 131-155. R. CORzo SÁNCHEZ, "Munda y las vias de comunicación en el Bellum Hispaniense", Habis 4 (1973), 241-252. C. Gonzalez Román y M. A. MARin Diaz, "Guerra civil y conflictos sociales en la P.H.U. en el 48-44 a.C.", en Actas I Congreso de Historia de Andalucía. Fuentes y Metodología. Andalucia en la Antigüedad (Córdoba, 1978), 131-141. J. M. ROLDAN HERVAS, "Guerra civil entre César y Pompeyo (49-31 a.C.)", en Historia de España Antigua II. Hispania Romana (Madrid, 1978), 155-173. V. DuRAN ReCıO, La batalla de Munda, Córdoba, 1984. V. DuRÁN RECIO y M. FerRerro LoPEZ, "Acerca del lugar donde se dio la batalla de Munda", Habis 15 (1984), 229-235. J. M. SolAna y A. Montenegro, "César en Hispania y la guerra civil con Pompeyo", en Historia de España 3. España romana (Madrid, 1986), 120-142. M. FERREIRO LOPEZ, "Las operaciones previas a la campaña del Segre", Habis 18-19 (1987-1988), 277-297. M. A. MAain Diaz, "En torno a la conjura contra Q. Casio Longino", en Actas del II Congreso Andaluz de Estudios Clásicos, I (Málaga, 1987), 185-190. J. M. RODDAZ, "Guerres civiles et romanisation dans la vallée de l'Ebre ", en Hommages à Robert Etienne (Paris, 1988), 317-388. J. MARTINEZ MERA, “Las ciudades hispanas ante la Guerra Civil», ETF(Hist) 11 (1998), 307-333. L. AMELA VALVERDE, "Cneo Pompeyo hijo en Hispania antes de la batalla de Munda", ETF (Hist) 13 (2000), 355-388; "Sexto Pompeyo en Hispania", Fll 12 (2001), 11-46; "Lépido en Hispania", HAnt 26 (2002), 35-58; "La participación de los mauretanos en la batalla de Munda», Aquila Legionis 3 (2002), 43-64; "La conspiración contra Casio Longino", RHM 93 (2003), 11-60.

3 PÉREZ, 1989, 33-39.

4 AlFOLDI, 1956, 66. Howgego, 1995, 68. De esta forma, las insignias o monogramas de las gentes gobernantes van substituyendo a los signos y símbolos de la soberania del Estado, fase que se acentúa tras L. Cornelio Sila (cos. I 88 a.C.) con la mención de varios generales con poderes extraordinarios al lado del responsable de la acuñación, y en su última fase, a finales de la República, la sola mención de los imperatores muestra como el alto poder ejecutivo usurpa los órganos de la administración en una clara progresión hacia la monarquia.

5 AMELA, 1990-1991, 196.- En ninguna de estas emisiones se menciona el nomen Pompeius, sino que su identificación estriba en la mención del cognomen en el caso de las amonedaciones de Pompeyo Magno, mientras que en las de sus dos hijos aparece el praenomen junto con el cognomen.

6 MILLAN, 1965, 298.

7 Vid: L. AmELA VALVERDE, “El desarrollo de la clientela pompeyana en Hispania». SHHA 7 (1989), 105117; "La clientela de Cneo Pompeyo Magno en Hispania», Historia y Vida 270 (1990), 90-97; La clientela de Cneo Pompeyo en Hispania. Diss. Barcelona, 2000; "La turma Salluitana y su relación con la clientela pompeyana", Veleia 17 (2000), 79-92; "La clientela de Cneo Pompeyo Magno en Hispania», Historia 16 297 (2001), 64-73; Las clientelas de Cneo Pompeyo Magno en Hispania, Barcelona, 2003. 
En el presente estudio se analiza las acuñaciones RRC 446 y 447 , ambas emisiones de plata, cuyos hallazgos son muy escasos ${ }^{8}$. Ambas emisiones se consideran emitidas en Hispania a favor de Pompeyo Magno durante el año 49 a.C. Su descripción es la siguiente:

\section{RRC 446: MAGN. PROCOS. y CN. PISO PROQ. ${ }^{9}$}

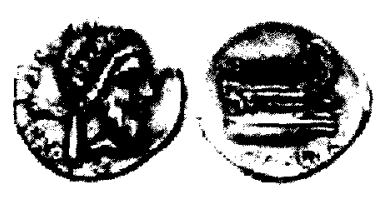

- RRC 446/1. Anv.: cabeza de Numa Pompilio ${ }^{10}$ a dra., con la inscripción NUMA en la diadema, detrás CN.PISO.PRO.Q. hacia abajo; grafila lineal. Rev.: proa de nave a dra., encima MAGN., debajo PRO.COS.; grafila lineal ${ }^{11}$.

Cuños de anverso: $[<30]$. Cuños de reverso: $[<33]$.

2. RRC 447'12: MAGN. PROCOS. y VARRO PROQ. ${ }^{13}$

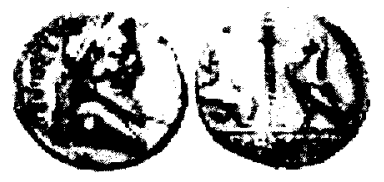

8 SteVenson, 1964, 638 Y 784. Crawford, 1974, 89.- ArÉVAlo y Campo, 1998, 331-332 señalan que estas emisiones tendrian un volumen de fabricación muy reducido, como se manifiesta en su ausencia en hallazgos y colecciones peninsulares, a excepción del tesoro de Liria (44 a.C.), en el que hay tres ejemplares de la emisión de Calpurnio Pisón en un conjunto total de 954 monedas, por lo que igualmente manifiestan, aunque de manera indirecta, que estas emisiones no habrian sido realizadas en la Península lbérica.

9 Rolland, s.d., 193. Cohen, 1857, 261; 1930, 3. Babelon, 1886, I 303-304. Grueber, 1910, 361. Sydenhaim, 1952, 172. Belloni, 1960, 214. Millán, 1965, 295. Gil FArRés, 1966, 260. MiChel, 1967, 45. SEaby, 1967, 103. Banti y Simonetti, 1972, 11. Campo, 1973, 60. Crawford, 1974, 463. Carson, 1978, 59. Battenberg, 1980, 82. Amela, 1990-1991, 181-182; 1999, 17. Martini, 1995, 114. Sear, $1998,7$.

10 ZEHNACKEA, 1973, || 987-988 ofrece un comentario estilistico sobre este retrato.

11 BARTULI, Botre y FABRIZI, 1997, 96 analizan un ejemplar de esta emisión, de 3'67 gr, con la siguiente composición: 98 '53\% de Ag, 0'50\% de $\mathrm{Pb}, 0$ '31\% de Au y 0'66\% de Cu. Por su parte, WALKER, 1980,67 analiza cinco ejemplares de las emisiones RRC 446/447, sin individualizar, que tenian un 96'5\% de Ag, con una desviación estándar de $0^{\prime} 79 \%$ con relación a otras acuñaciones de este periodo. A destacar que este investigador señala que en el $82-40$ a.C. (media de $95^{\prime} 9 \%$ ) la fineza en las monedas de plata es más alta en las emisiones hispánicas y más bajas en las de Oriente. Un dato más a tener en cuenta.

12 SCHEers, $1969,42-43$ y $145 ; 1976,199 ; 1977,188,434$ y 439 . COLBERT De BeAulieu, 1977,188 y 434 señalan la existencia de un bronce galo, perteneciente al conjunto de monedas del caudillo Arda (de $16 \mathrm{~mm}$ y peso 1,95 gr a 4,30 gr) del pueblo de los Treveri (BN 8839-8840) en el oppidum de Tetelbierg, inspirado en una acuñación romano republicana, que reproduce en su anverso el correspondiente a la emisión de Varrón, con gran fidelidad (sólo los extremos fluctuantes de la diadema no aparecen reflejados).- Su descripción es la siguiente. Anv.: Cabeza diademada y barbuda a dra.; delante de la cara, el pie de letras centrifugas, la leyenda ARDA; línea de puntos. Rev.: Caballo cabalgando a dra.; línea de puntos.

13 Rolland, s.d., 87. Comen, 1857, 261 y 310-311; 1930, 2. Babelon, 1886, II 343 y 486. GRUeBer, 1910, 362. Sydenham, 1952, 172. Belloni, 1960, 214. Millan, 1965, 295. Gil Fariés, 1966, 260. Michel, 1967, 44. Seaby, 1967, 103. Banti y SimOnetti, 1972, 9. Campo, 1973, 60-61. Crawford, 1974. 463. Carson, 1978, 59. Batteneerg, 1980, 82. Perez, 1989, 124. Amela, 1990-1991, 182; 1999, 17. Martini, 1996, 114. Sear, 1998,7 
- RRC 447/1a: Anv.: busto de Júpiter ${ }^{14}$ Terminal, a dra., llevando una diadema; detrás VARRO.PRO.Q. hacia abajo; grafila de puntos. Rev.: cetro en el centro, entre águila a dra. y delfín a izq.; en el exergo MAGN.PRO.COS.; grafila de puntos.

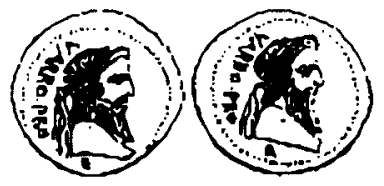

- RRC 447/1b. Anv.: igual. Rev.: igual al anverso ${ }^{15}$. Esta variante se debe a un error en la emisión ${ }^{16}$.

Cuños de anverso: $[<30]$. Cuños de reverso: $[<33]$.

Estas dos acuñaciones han planteado numerosos problemas en cuanto a su cronología y a su lugar de fabricación. Siempre, de manera conjunta ${ }^{17}$, se han fechado en el año 73 a.C., durante la guerra sertoriana ${ }^{18}$; en el año 67 a.C., con motivo de la campaña contra los piratas ${ }^{19}$; o en el año 49 a.C., con ocasión del conflicto entre Cn. Pompeyo Magno (cos. I 70 a.C.) y C. Julio César (cos. I 59 a.C.) ${ }^{20}$. Crawford ha podido demostrar de manera irrefutable que ambas acuñaciones deben situarse en los años 49/48 a.C., gracias al testimonio del tesoro de San Niccolo di Villola (45 a.C.), donde las monedas de Varrón y Calpurnio Pisón son las más antiguas. No ha de extrañar, puesto que en los tesoros de los años setenta, sesenta y cincuenta no se encuentra ninguna pieza procedente de estas emisiones, lo que evidencia claramente que pertenecen al período de la guerra civil ${ }^{21}$.

En cuanto al lugar de acuñación, es sorprendente la afirmación de Crawford de considerar que Varrón no pudo haber sido proquaestor en Hispania durante los años 49/48 a.C. pues considera que éste sirvió a Pompeyo Magno en la Península únicamente durante la guerra sertoriana ${ }^{22}$, por lo que no

14 ZEHNACKER, 1973, II 744-746 y 797-798 señala la existencia de seis tipos distintos de representación de Júpiter en la numismática republicana, correspondiendo la presente emisión al tipo cuarto, de la que es la única representante. Se trata de una imagen que generalmente se acuña en tiempos de condiciones precarias e infrecuentes, como RRC 447. ALTERI, 1990, 59 señala que la presencia de Júpiter no es muy frecuente en las acuñaciones del s. I a.C.

15 Stannard, 1995, 361-362 ofrece el listado de este tipo de acuñaciones durante la República Romana.

16 Grueber, 1910, 363. Crawford, 1974, 89 señalan que su presencia, por una evidente carencia de troqueles, sugiere que fue producida en condiciones no pacíficas. - Por el contrario, SEAR, 1998,8 considera que debido a que monedas de este tipo son generalmente plateadas o de bajo metal no son más que falsificaciones contemporáneas, pues este investigador considera que estas piezas se acuñaron en Grecia, es decir, en unas circunstancias más tranquilas que en Hispania.

17 A partir de la carrera de M. Terencio Varrón, monetario de RRC 447.

18 STEVENSON, 1964, 168

19 COHEN, 1857, 265 Y 311; 1930, 2-3. SteVENSON, 1964, 638 y 784.

20 Rolland, s.d., 87, 171 y 193. StEVENSON, 1964, 843.

21 Grueber, 1910, 351 y 361. CRAWFORD, 1974, 89.

22 BROUGHTON, 1952, 95 y 100. 
pudo amonedar en un momento posterior ${ }^{23}$. De esta forma, este investigador considera que ambas emisiones (la de Varrón y la de Calpurnio Pisón) debieron fabricarse en Grecia por una ceca móvil durante la campaña que desembocaría finalmente en la batalla de Pharsalus (48 a.C.) $)^{24}$, sin entrar tan siquiera a discutir la teoría de Alföldi, quien considera que estas monedas fueron emitidas en África ${ }^{25}$.

La participación de Varrón en los acontecimientos de la Ulterior a favor de la causa de Pompeyo Magno durante el año 49 a.C., es muy conocida ${ }^{26}$ Pompeyo Magno, desde el año 55 a.C., era gobernador de las dos Hispanias, Citerior y Ulterior, aunque ejercía el cargo in absentia, ya que permanecia en los alrededores de Roma para controlar la política de la Ciudad Eterna. En su lugar, envió una serie de legados (App. BCiv. 2, 18. Dio Cass. 39, 39, 4. Liv. Per. 110, 1. Plut. Caes. 36, 1; Pomp. 53, 1-2. Vell. Pat. 2, 48, 1) para su administración, y de esta forma se convirtió en el precursor de la forma de gobernar las provincias imperiales durante el Principado ${ }^{27}$.

Por tanto, es perfectamente asumible que en el año 49 a.C. se acuñase moneda en Hispania a favor de la causa pompeyana ${ }^{28}$ con el objeto de pagar las numerosas tropas que se encontraban acantonadas en el territorio ${ }^{29}$, más los nuevos reclutamientos realizados a causa del estallido del conflicto. $O$, mejor in-

23 CrawFord, 1974, 89-92

24 Crawford, 1974, 92. Sear, 1998, 7-8. Catalli, 2001, 253.- Se da la casualidad que Crawford utiliza para sus descripciones ejemplares encontrados en la Península Ibérica (BMCRR Spain 62, 64 y 67 respectivamente)

25 ALFÖLDI, 1966, 25-26 considera que estas acuñaciones habrian sido emitidas para el mantenimiento de una flota en África del Norte en los años 49-48 a.C., antes del desenlace de la batalla de Pharsalus. Vid: A. Alfol.DI, "luba I. und die Pompeianer in Afrika (Zu den Münzquellen der Geschichte der Bürgerkriege, l)", SM 8 (1958), 103-108 y 9 (1959), 1-5.

26 Fuentes en Brougthon, 1952, 253.

27 Jones, 1951, 112-113. Caldwell, 1953, 957. Crawford, 1982, 177. Hidalgo, 1986-1987, 97-98.

26 Rolland, s.d., 87, 171 y 193. Grueber, 1910, 348 y 361-362. SYdenham, 1952, LXVI y 172. Gil FARRES, 1960, 233 Y 260. MATTINGLY, 1963, 53. MiCHEL, 1967, 45. ZeHNACKER, 1973. 11 920, 983 y 987. SUTHERland, 1974, 89. CARSON, 1978, 59. BATtenBERG, 1980, 83 y 190. WALKER, 1980, 67. VillarongA, 1987, 239. Foss, 1990, 13. Perez, 1989, 124. Burnet, Amandry y Ripolles, 1992, 9 y 26. Fernández Fernandez y CaLICO, 2002, 170. GARCIA-Bellido y CRuces, 2002a, 131 (pero niegan este extremo en 2002b, 322, y no consideran la existencia de acuñaciones pompeyanas en Hispania en el año 49 a.C. en 2002a, 175) las consideran igualmente de Hispania.- MARTINI, 1996, 114 las considera de ceca incierta, aunque se pregunta si fueron emitidas en Hispania

29 La lex Trebonia otorgó a Pompeyo iguaimente un ejército (App. BCiv. 2, 18. Flor. 2, 13, 12. Plut. Caes. 28,5 ), formado por cuatro legiones, para cuyo mantenimiento sacaba del erario público mil talentos anuales (Plut. Caes. 28, 5).- MUÑiz Coello, 1982, 89 considera que Afranio y Petreyo disponía de cinco legiones, más 80 cohortes y 5.000 socii (Caes. BCiv. 1, 39, 1), que suponían un gasto anual de 5.630 .000 denarios, y la cantidad hasta completar los 1.000 talentos comprenderian el coste del transporte de estas tropas. En realidad, habia seis legiones (Cic. Fam. 16, 2, 4), a la que hay que añadir una séptima (Caes. BCiv. 1, 85, 6), la legio Vernacula, debido a que Muñiz Coello únicamente toma en cuenta el ejército de la Citerior.Crawford, 1974, 696 n. 5 establece correctamente que Pompeyo Magno tenía en el año 49 a.C. siete legiones en Hispania, pero considera, erróneamente, que Pompeyo pagaria de su propio bolsillo el mantenimiento de las dos legiones otorgadas en el año 52 a.C. y la legio Vernacula, al establecer un coste de 1.500.000 de denarios por legión, y tener un presupuesto aprobado por el Senado de tan solo 6.000.000 de denarios anuales.- MATTINGLY, 1977, 207 acertadamente señala que el desembolso anual a partir del año 52 a.C. era de 6.000 .000 de denarios anuales para las seis legiones, es decir, 1.000 .000 de denarios para cada legión. 
cluso, hacer frente en un primer momento a los gastos financieros de la guerra en sí, dejando para un momento posterior la retribución de los soldados.

Precisamente, uno de los problemas principales que Pompeyo tenía en Oriente fue la recaudación de fondos para pagar los gastos derivados de la contienda. Para ello, creó nuevos impuestos y otras exacciones en todas las ciudades y provincias que tenía bajo su control, así como por forzar el pago de atrasos y adelantos a las compañias de publicanos. Los particulares también efectuaron contribuciones, de forma voluntaria o forzosa: Cicerón tenía sus cuentas en estado caótico en el año 47 a.C. debido a sus subvenciones "a la causa»30.

En este sentido, Crawford ha señalado numerosas emisiones locales que servirian a este propósito ${ }^{31}$, aunque han de rechazarse las atribuciones efectuadas a la Liga Tesalia ${ }^{32}$ y a diversas comunidades del Asia Menor ${ }^{33}$, y sólo se mantiene la de las ciudades ilirias de Apollonia y Dyrrhachium ${ }^{34}$. Ante todo, Pompeyo se basaría en el circulante ya existente más que en la amonedación de denarios romanos por parte de sus partidarios (RRC 444-446).

En este apartado, hay que llamar la atención que de las amonedaciones republicanas provinciales de los años 49/48 a.C. (RRC 444-447), las únicas que hacen alusión a Pompeyo (como procónsul) son precisamente las que se consideran en este trabajo ${ }^{35}$. RRC 444 presenta a Q. Sicinio como triunviro monetario y a C. Coponio como pretor, mientras que RRC 445 señala a los cónsules del año, L. Cornelio Léntulo y C. Claudio Marcelo como responsables de la acuñación ${ }^{36}$. Es una evidente indicación de quien era el verdadero responsable de la emisión: Pompeyo ${ }^{37}$.

30 Leach, 1978, 188. Amela, 2003, 250 (App. BCiv. 2, 49. Caes. BCiv. 3, 3, 2; 3, 4, 5. Cic. Att. 11, 13, 4)

3 CRAWFORD, $1985,245$.

32 KLOSE, 1998, 337-338.

33 KinNs, 1987, 119 n. 66. - Por contra, en el año 49/48 a.C. siguieron efectuándose las emisiones regutares de cistótoros en la provincia de Asia, a cargo de C. Fanio (pr. 50 a.C.?), en las cecas de Apamea (Stumpf 57), Éfeso (Stumpf 58-59), Laodicea (Stumpl 60-62) y Tralles (Stumpf 63-67), a las que hay que añadir la copiosa amonedación de cistóforos en el taller de Pérgamo (Stumpf 68) a cargo de Q. Cecilio Metelo Pio Escipión (cos. 52 a.C.), suegro de Pompeyo y gobernador de la provincia de Siria, destinada al pago de sus fuerzas militares, como indica claramente el tipo del reverso, en el que aparece el estandarte de un águila legionaria.

34 PiCARD y GJongeCAl, 2000, 157 confirman que este tipo de emisiones cesan en el año 48 a.C., coincidiendo con las operaciones militares que finalizarán en la batalla de Pharsalus, pero sin indicar ielación alguna con los bandos en conflicto.

35 SEAR, 1998, 8 señala que este título fue usado por Pompeyo Magno en su acuñación áurea, RRC 402/1, que ilustra la naturaleza poco ortodoxa del poder que éste disfrutaba mucho antes del estallido de la Guerra Civil. Sobre esta emisión, Vid: H. CAStritus, "Zum Aureus mit dem Triumph des Pompejus», JNG 21 (1971), 25-35. L. Amela Valverdoe, “El áureo de Cn. Pompeyo Magno (RRC 402), acuñado en Amisos (Ponto)", GN 140 (2001), 5-13

${ }_{36}$ De hecho, el verdadero responsable, al menos para la emisión RRC 445/1-2, de Apollonia, fue el cuestor T. Antistio (Cic. Fam.13, 29, 4).

37 Esto no quiere decir que, forzosamente, ambas emisiones fueran efectuadas en Hispania pues, desde el 1 de enero del año 48 a.C., Pompeyo era el comandante en jefe del ejército republicano. Pero, si se mantiene el año 49 a.C. como cronologia de estas acuñaciones, en comparación con las leyendas republicanas del mismo año (RRC 444-445), apuntan a un origen diferente a éstas, es decir, a la Península Ibérica. 
Varrón es considerado por César el representante pompeyano en la Ulterior en el año 49 a.C. (Caes. BCiv. 1, 38, 2; 2, 17, 1), aunque los legados en aquel momento fuesen realmente L. Afranio (cos. 60 a.C.) y M. Petreyo (vir pr. $)^{38}$. Por tanto, si se considera acertado que Varrón acuñó moneda en Hispania, forzosamente lo debió ser en la región que tenía a su cargo. Si en la Ulterior se amonedó, sería extraño que no se hiciera igualmente en la Citerior, sobre todo si se considera el gran número de efectivos militares que existían en ella para hacer frente al ejército de César ${ }^{39}$. De esta manera, si Varrón acuñó para si mismo y sus tropas, es de suponer que Calpurnio Pisón haria lo mismo para las fuerzas de Afranio y Petreyo ubicadas en la Citerior ${ }^{40}$.

Una solución a la ausencia de estas piezas en la Península lbérica parece aportarla la emisión de Q. Labienus Parthicus Imp. ${ }^{41}$ (RRC 524/1 áureo y $524 / 2$ denario, ambos del año 40 a.C.), de la cual a pesar de haberse registrado únicamente 34 denarios y 3 áureos, ha dado un total de ocho cuños de anverso (ocho para el denario y dos para el áureo) y veintitrés de reverso (veinte para los denarios y tres para los áureos), lo que indica que a pesar del poco número de monedas conservadas la acuñación no debió ser precisamente pequeña $a^{42}$. Para Hersh, posiblemente aconteció que estas monedas fueron retiradas de la circulación y/o fundidas a la muerte de Labieno (39 a.C.), debido a su carácter fundamentalmente antirromano, como se puede comprobar fácilmente en su leyenda e iconografía. Quizás fuera este el destino de gran parte de las emisiones pompeyanas.

La mención de Calpurnio Pisón, y no de Afranio y Petreyo, los legados pompeyanos (Caes. BCiv. 1, 38, 1), pudiera responder en un principio a que cuando comenzó a emitirse estos denarios, los dos últimos personajes se encontraban ya en movimiento con sus tropas contra César, que desembocaría en la batalla de llerda ${ }^{43}$. Más bien, probablemente, al ser Calpurnio Pisón y Varrón, como proquaestores, los encargados de las finanzas y, por

${ }^{38}$ Brougthon, 1952, 252-253. Vid: L. Amela VAlVerde, "Pompeyo Magno y el gobierno de Hispania en los años 55-50 a.C.", HAnt 25 (2001), 95-124

39 Las fuerzas militares de la Uiterior estarian compuestas por dos legiones (Caes. BCiv. 2, 18, 1) y treinta cohortes auxiliares (Caes. BCiv. 2, 18, 1), unos 25.000 hombres. Mientras, en la Citerior, habia cinco legiones (Caes. BCiv. 1, 39, 1; 1, 83, 1), ochenta cohortes de caballería y 5.000 jinetes (Caes. BCiv. 1 , $39,1)$, unos 70.000 hombres. Sobre las fuerzas militares pompeyanas en Hispania, vid: J. HARMAND, «César et l'Espagne durant le second bellum civile", en Legio VII (León, 1970), 181-203. J. M. ROLDÁN HERVÁS, "El elemento indigena en las guerras civiles en Hispania: aspectos sociales", HAnt 2 (1972), 77-123. J. RoDRIGUEZ GONZALEZ, "Legiones romanas en el Mediterráneo Occidental. Las unidades legionarias en Hispania durante la guerra civil del 49 al 45 a.C.", en El Mediterráneo: hechos de relevancia histórico-militar y sus repercusiones en España. $V$ Jornadas Nacionales de Historia militar (Sevilla, 1995), 155-167. L. AMELA VALVERDE, "Efectivos del ejército pompeyano de Hispania (49-44 a.C.)”. RHM 89 (2000), 11-56.

40 BABELoN, 1886, II 486 (Varrón para Petreyo). Grueber, 1910, 361.

41 Q. Labieno, hijo del general pompeyano T. Labieno (tr. pl. 63 a.C.), fue comisionado por el cesaricida Casio Longino a buscar apoyo entre los Partos para luchar contra Octaviano y Marco Antonio (cos. I 44 a.C.), de tal forma que en el año 40 a.C. invadió las provincias de Siria y Asia al frente de un ejército de este pueblo.

42 Hersh, 1980, 47.- Crawford, 1974, 529 da las siguientes cifras: cuños de anverso: [<30], cuños de reverso: $[<33]$.

${ }^{43}$ FABRICOTTI, 1968, 37 considera que las acuñaciones de ambas series fueron realizadas en llerda, en base seguramente a que aqui se acaeció la batalia del mismo nombre, pero no parece lógico esta atribu- 
tanto, responsables directos de las emisiones, lo harian a nombre del procónsul ausente y gobernador legítimo de ambas provincias: Pompeyo Mag$\mathrm{no}^{44}$. De ahí, la no mención ni de Afranio ni de Petreyo.

Parece tratarse de un caso paralelo a la acuñación RRC 366/1-4, del año 82/81 a.C., en la que la presencia de dos quaestores para el gobernador silano de Hispania C. Annio (pr. 82 a.C.), L. Fabio Hispaniense (q. 81 a.C. ${ }^{45}$ y C. Tarquitio (q. 81 a.C.), sería ininteligible si el primero no fuera el responsable a la vez de ambas provincias peninsulares, Citerior y Ulterior $^{46}$. De esta forma, se advierte que tanto la Citerior como la Ulterior tendría su propio proquaestor, lo que implica que si bien las dos estarían regidas por un mismo gobernador, Pompeyo Magno, la administración permanecería separada ${ }^{47}$.

Crawford menciona que ambas acuñaciones son de un estilo y una fabricación muy diferente, por lo que presumiblemente debieron de realizarse en dos lugares distintos ${ }^{48}$. Posiblemente, la moneda de Calpurnio Pisón se acuñaría en Tarraco o Carthago Nova, mientras que la de Varrón en Corduba $^{49}$. Esta teoría está basada en que estas ciudades son las más importantes (las "capitales") de las provincias de Hispania Citerior y Ulterior respectivamente ${ }^{50}$.

Por su parte, otros estudiosos consideran que Calpurnio Pisón amonedaría en llerda ${ }^{51}$, debido a su posible relación con la batalla homónima, mientras que Varrón efectuaría esta operación a su vez en Hispalis o Gades ${ }^{52}$, basado posiblemente en la mención de estas localidades en las fuentes clásicas durante la narración de los acontecimientos militares acontecidos en el año 49 a.C., en especial el De bello civili de César. La cita de éstas o de

ción, ya que implicaría una amplia concepción estratégica del conflicto por parte del bando pompeyano que no parece existir, al igual que no explica la emisión de Varrón, ya que las fuentes unánimemente lo presentan en la Ulterior (exactamente en la Bética).

44 Campo, 1973, 62. BRougthon, 1986, 47. Hart, 1996, 55-56. La utilización de este título es característica de las emisiones "pompeyanas" de la primera fase de la Guerra Civil, como signo de legitimidad, habida cuenta que la mayor parte de ellas fueron acuñadas lejos de la ceca oficial: Roma.

45 Sobre este personaje, vid: F. HINARD, "Philologie, prosopographie et histoire à propos de Lucius Fabius Hispaniensis", Historia 40 (1991), 113-119.

46 CRAWFORD, 1974, 386.

47 AMELA, 1990-1991, 183.

48 Crawford, $1974,92$.

49 AMELA, 1990-1991, 183; 1999, 20.

50 Sobre estas ciudades, vid: A. IBÁNez CAStro, Córdoba hispano-romana (Córdoba, 1983). R. C. KNAPP, Roman Corduba (Berkeley, 1983). J. F. RodRiguez NEILA, Historia de Córdoba 1. Del amanecer prehistórico al ocaso visigodo (Córdoba, 1988). G. Alfóldy, Tarraco (Tarragona, 1991). A. PAieto ARCIEGA, "Tarraco", DArch 10 (1992), 79-93. J. RuIz DE ARBullo, “Tarraco, Carthago Nova y el problema de la capitalidad de la Hispania Citerior republicana", en Miscel.lània Arqueològica a Josep M. Recasens (Tarragona, 1992), 115-130. S. Ramallo et Alil, "Carthago Nova", DArch 10 (1992). 105-110. J. Gimeno, «Plinio, Nat. Hist. III, 3, 21: reflexiones acerca de la capitalidad de Hispania Citerior", Latomus 53 (1994), 39-79.

51 Grueber, 1910, 361. Banti y Simonetti, 1972, 11.

52 Grueber, 1910, 363. Banti y Simonetti, 1972, 9. Saez Balaño y Blanco Villero, 1996, 76. 
otras poblaciones relacionadas con los hechos bélicos no ofrecen seguridad alguna para establecer el taller donde se acuñaron estas emisiones ${ }^{53}$. Sea como fuere, habría de descartarse que estas emisiones hubieran sido producidas en un taller itinerante, es decir, en un campamento militar.

En cuanto a los monetales, Cn. Calpurnio Pisón (cos. 23 a.C.) no es un personaje de genealogía desconocida ${ }^{54}$, sino que se trata del hijo del conocido quaestor pro praetore $\mathrm{Cn}$. Calpurnio Pisón, muerto en Hispania en el año 64 a.C. ${ }^{55}$ y, por tanto, no debe ser confundido con M. Pupio Pisón Frugi Calpurniano (cos. 61 a.C.), que fue lugarteniente de Pompeyo Magno en la guerra contra los piratas ${ }^{56}$. No se trata de una paradoja (su padre fue muerto por clientes de Pompeyo en Hispania [Sall. Cat. 19, 5] ${ }^{57}$ ), ya que la familia de los Calpurnii Pisones siempre estuvo en las filas de los defensores de la Repúbli$\mathrm{ca}^{58}$. Participó como proquaestor de Pompeyo Magno en Hispania (49 a.C.), luego estuvo con los republicanos en África (46 a.C) y, más tarde, siguió a M. Junio Bruto (pr. 44 a.C.) y C. Casio Longino (pr. 44 a.C.) en la batalla de Philippi (42 a.C.); perdonado por C. Julio Octaviano (cos. I 43 a.C.), fue nombrado cónsul en el año 23 a.C. sin haberlo solicitado (Tac. Ann. 2, 43, 1) ${ }^{59}$.

La aparición de la efigie del rey Numa Pompilio (de tipo helenístico desde el punto de vista artístico ${ }^{60}$ ) en el anverso se debe a la antigua pretensión de la gens Calpurnia de descender de Calpus, hijo de Numa (Dion. Hal. 2, 76, 5. Plut. Numa 21, 2-3)61. La presencia de retratos de antepasados, con clara intencionalidad propagandística, es patrimonio de los últimos tiempos de la República desde los años cincuenta del último siglo a.C., al desaparecer el sentido de subordinación al Estado, y se refleja en la proclamación por parte de varias familias aristócratas de su descendencia de los antiguos monarcas de Roma, a pesar de que la realeza estuvo siempre mal vista durante la República ${ }^{62}$. Esta amonedación es un buen ejemplo de cómo las nuevas corrientes de pensamiento en la oligarquia romana se formaban sobre la base

53 Chaves, 2001, 29 - Sydenham 1952, XLVII señala que los lugares donde se efectuaron estas emisiones son indeteminables.

54 SYME, 1960, 12.

55 SYME, 1989, 368.

56 BABELON, 1886, 1303

57 Vid: L. Amela Valverde, "El asesinato de Cn. Calpurnio Pisón”, Gerión 20/1 (2002), 255-279.

58 SYME, 1989, 368. Sobre la relación entre Pompeyo Magno y esta familia, vid: E. S. Gruen, "Pompey and the Pisones", CSCA 1 (1968), 155-170. Sobre esta gens: I. HofMANN-LOEBL, Die Calpurnii. Politischen Wirken und Familiäre Kontinuität, Frankfurt am Main, 1996.

59 CRAWFORD, 1974, 543 considera que pudo ser también el monetario responsable de la acuñación RRC 547

to Bernareggi, 1963, 98

61 Rolland, s.d., 87. Babelon, 1886, 1303 y ll 486. Grueber, 1910, 361. Alfoldi, 1956, 80. Alteri, 1990, 199. Bernareggi, 1963, 97. Millan, 1963, 295. Stevenson, 1964, 166, 168 y 579. Seaby, $1967,103$. FABBRICOTTI, 1968, 37. BANTI Y SIMONETII, 1972, 11. CAMPO, 1973, 60. ZEHNACKER, 1973, I 524 y II 987. CRAWFord, 1974, 738. Wiseman, 1974, 155. Battengerg, 1980, 84. Perez, 1986, 255-256. Wallace-Hadrill, 1986, 82-83. Alteri, 1990, 199. Sear, 1998, 7. Catalli, 2001, 198. También se decian descendientes de Numa los Pomponii, los Pinarii y los Mamercii (Plut. Num. 22, 2).

62 ALFÖLDI, 1956, 77-80. La diadema real era una dificultad para la representación de un monarca en las monedas, ya que ello significaria deseos de tiranía, por lo que Calpurnio Pisón la disimuló poniendo directamente el nombre del rey Numa. 
del recuerdo histórico, así como indica una rehabilitación de la monarquía, que en el caso de Numa recuerda una perdida edad de oro ${ }^{63}$.

Más conocido que Calpurnio Pisón es $M$. Terencio Varrón (vir pr. ${ }^{64}$, el famoso escritor, gran amigo de Pompeyo $\mathrm{Magno}^{65}$, quien más tarde estuvo presente en la batalla de Pharsalus (48 a.C.). Después de este enfrentamiento, Varrón se reconcilió con César y se retiró posteriormente a sus estudios literarios, falleciendo en el año 28 a.C.

Desde un punto de vista alegórico, ambos denarios reflejan el estado militar de las fuerzas pompeyanas en el Mediterráneo en el año 49 a.C. En el reverso de la moneda de Calpurnio Pisón se alude a las batallas navales de Pompeyo Magno y a su poder marítimo, relacionado con su campaña contra los piratas (motivo de la proa); mientras el reverso de la moneda de Varrón refiere los éxitos o las fuerzas de tierra y mar de Pompeyo Magno (representados por los motivos respectivos del águila y del delfín, que están presididos por el cetro, símbolo del mando) ${ }^{66}$. Desde un punto de vista más general, el primer denario refleja la flota de Oriente y el segundo las legiones de Occidente, con lo que se obtiene el dispositivo estratégico de Pompeyo Magno en el Mediterráneo ${ }^{67}$.

El águila y el delfín de Varrón son respectivamente los animales emblemáticos de los dioses Júpiter y Neptuno ${ }^{68}$, que representarían las fuerzas de

63 Perez, 1986, 256; 1989, 50.

${ }^{64}$ Grueber, 1910, 362. Battenberg, 1980, 82. Sear, 1998, 8 consideran que no puede tratarse de este personaje, puesto que, al llegar a pretor (en fecha indeterminada), difícilmente puede asumirse que figurase en las monedas como proquaestor, por lo que sugiere que se trata de otro miembro de la gens Terentia, probablemente un hijo suyo. Más bien, si los legados de Pompeyo Magno en Hispania eran Afranio y Petreyo, uno para cada provincia. Hispania Citerior y Ulterior respectivamente, y como el último también había llegado al grado de pretor, quizás, para diferenciar las diferentes competencias de los legados, pues parece que éstos eran oficialmente denominados legatus propraetore, se utilizara la designación que aparece en las monedas, que muy posiblemente coincida con el hecho de que Calpurnio Pisón habia sido recientemente cuestor, como acontece con uno de los monetarios de Cneo Pompeyo hijo, M. Minacio Sabino (RRC 470). Quizás si el hijo de Varrón estuviera con él en la Bética hubiera sido mencionado en el relato de Cessar (Caes. BCiv. 2, 17, 1-21, 4). Recientemente, gracias a una inscripción de Carthago Nova (HEp 3 250), se ha documentado la existencia de un legatus pro praetore, de nombre C.? Herius Hispa., quizás un legado pompeyano perteneciente a este periodo. De ser asi, vendria a confirmar la titulatura oficial que tendrian Afranio y Petreyo, a la vez que supondria que habría más legados en Hispania de los conocidos por las fuentes literarias.- Sea como fuere, BATTENBERG, 1980, 84 señala acertadamente que Calpurnio Pisón no aparece citado en las operaciones militares acontecidas en la Hispania Citerior.

65 Sobre la relación entre ambos personajes, vid: W. S. ANDERSON, Pompey, his friends, and the literature of the first century BC. Berkeley, 1963. R. ATsBuRY, "Varro and Pompey", CQ 17 (1969), 403-407. F. DELLA CORTE, “Letterati di parte pompeiana", en La repubblica romana da Mario a Silla a Cesare e Cicerone. Atti del convegno (Mantova, 1990), 29-42.

66 Babelon, 1886, I 303 y II 486. Gateber, 1910, 361-362. Burzio, 1961, 131. Bernareggi, 1963, 97. MiLlá, 1963, 295. Stevenson, 1964, 339 y 353. Seaby, 1967, 103. Banti y Simonetti, 1972, 9 y 11. Campo, 1973, 60 y 62. Battenderg, 1980, 85 y 190. Alteri, 1990, 60, 171-172 y 179. Sauron, 1994, 468. SeAR, 1998,7

67 Grueber, 1910, 362. MiLlán, 1963, 295. Campo, 1973, 60 y 62. Difícil de ver, como a veces se ha planteado, un recuerdo de las anteriores campañas de Pompeyo Magno contra los piratas y contra el rey Mitrídates VI de Ponto, pues se basa en la conjetura de que estas piezas fueron emitidas en Oriente.

${ }^{68}$ STEVENSON, 1964, 339, 352 y 770 . PEREZ, 1989, 63 y 124. El delfin puede ser igualmente un atributo de la Venus chipriota, o incluso indicar una ciudad maritima.- STEVENSON, 1964, 771 señala que, a su vez. la proa (de un barco) puede simbolizar una población marítima, sino también a la propia Roma. 
tierra y mar, los símbolos de dominación terra marique ${ }^{69}$, demostrando así un interesante sincretismo ${ }^{70}$. Por otro lado, el busto de Jupiter Terminalis ${ }^{71}$, defensor de los límites y las fronteras, recuerda los poderes conferidos por el Senado a Pompeyo Magno ${ }^{72}$.

Un análisis más detenido de la moneda de Varrón muestra un mensaje mucho más trascendental: Júpiter aparece con una diadema, el símbolo incuestionable de la monarquía, al igual que la efigie de $\mathrm{Numa}^{73}$, lo cual indica que la protagonista de la acuñación no es la República, sino el propio Pompeyo Mag$n^{74}$. Más aún, tanto el propio nombre de Pompeyo como el de su cargo, grabados en la moneda, bajo las imágenes de dominio y de autoridad simbolizadas por el cetro ubicado entre el águila y el delfín, quieren reflejar las recientes victorias del imperator Pompeyo Magno, es decir, de su propia gloria, vencedor terra marique, a la vez tanto Júpiter como Neptuno (de donde su hijo Sexto Pompeyo se definirá como «hijo de Neptuno") $)^{75}$. No en vano el cetro es el símbolo del poder de los antiguos reyes, especialmente en el campo de la justicia, que desde un punto de vista numismático aparece reflejado en las imágenes de las divinidades, particularmente en la del rey de los dioses, Júpiter ${ }^{76}$.

Ni Calpurnio Pisón ni Varrón hacen mención a la autoridad senatorial ${ }^{77}$ (reflejada por la abreviatura S.C. ${ }^{78}$. El Senado, en este momento histórico,

69 Crawford, 1974, 738. Catalli, 2001, 198.- Momigliano, 1942, 64 señala que la fórmula terra marique, de origen griego, aparece tardiamente en Roma, con Pompeyo Magno (Cic. Balb. 16), y se utilizó de una manera limitada. Vid: L. AMELA VALVERDE, "Terra marique. Un dato pasado por alto en relación con Pompeyo Magno (Dio Cass. 42, 5, 2)», Helmantica, en prensa.

70 Perez, 1989,63

71 ALTERI, 1990, 60 puntualiza que no todos los estudiosos de la religión romana están de acuerdo sobre este particular pues, por ejemplo, STEVENSON, 1964, 784 ya señala la posibilidad de que se tratase de Quirinus.- Grueber, 1910, 362-363. Zehnacker, 1973, 1 525. Battenberg, 1980, 84. Alteri 1990, 60 n. 24 señalan la posibilidad que la imagen de Jupiter Terminalis sea un juego de palabras etimológico con el gentilicio Terentius de Varrón, al derivar este mismo la palabra terminus de terra o terere (Varr. Ling. lat. 5, 21), mientras que su alumno Verrio (Fest. pp. 350-351) consideraba que terentum provenía de terra.

72 Perez, 1989,63 y 124

73 COHEN, 1857, 310-312 propuso, sin éxito, que en el anverso de la moneda de Varrón, más que Jupiter Terminalis, representaba la imagen del monarca Numa, al compararla estilísticamente con la figuración de la moneda emitida por Calpurnio Pisón.

74 Amela, 1999, 22.- SAURON, 1994, $468-469$ considera que la presencia de la imagen de Júpiter terminalis no es más que la afirmación de la primacia de Júpiter Capitolino como dios supremo y favorecedor de las victorias de Roma, y garante de la perennidad de las fronteras del Imperio. Para este investigador, la representación monetaria reuniria en una sola figura las dos deidades cuyas estatuas ocupaban la cella central del templo capitolino de Roma: Júpiter y Terminus, que podia presentar la apariencia de un herma acéfalo, al menos desde la restauración del monumento por Q. Lutacio Cátulo (cos. 78 a.C.), a la que quizás Varrón no fue ajeno. Sea como fuere, esta representación proclamaria el poder universal de Pompeyo Magno, como delegación terrestre de la realeza celeste de Júpiter; Sauron considera la representación de Terminus la expresión de la estabilidad de esta realeza y del mundo asi dirigido.

75 Vid: E. La RocCA, “Pompeo Magno Novos Neptunus", BCAR 92 (1987-1988), 265-292. L. AmELA VALVERDE, "La serie de Q. Nasidius (RRC 483)", GN 148, (2003), 9-23. Los denarios de Sexto Pompeyo prefiguran la amonedación imperial, en cuyo anverso se reproduce el aspecto físico y en el reverso el aspecto moral

76 STEVENSON, 1964, 721-722.

77 CAMPO, 1973, 62.

78 La trasgresión de los códigos tradicionales revela el paso de una amonedación imperatorial a una imperial, en los que ya se puede apreciar la no-exigencia de la referencia a la autoridad emisora (el Senado) ya no es necesaria en las acuñaciones extraordinarias. 
era más bien un ente abstracto, al menos en lo que se refiere a la Península Ibérica, debido a la gran influencia que ejercía la gens Pompeia en ella, por lo que quizás no fuese necesario reflejar en ella alusión alguna al Senado, a pesar de que la emisión es de circunstancia ${ }^{79}$. Incluso, debido a la especificidad de Hispania, en manos de Pompeyo desde cinco años atrás, los legados establecidos en ella no consideraron que fuera necesario su mención, quizás porque en el momento de iniciar la producción de estas piezas Roma había caido en manos de César ${ }^{80}$.

De hecho, la única acuñación republicana que hace alusión al Senado es la RRC 444 (49 a.C.), aunque otra del mismo año, RRC 445, no lo hace ${ }^{81}$, quizás porque en esta última se mencione a los cónsules huidos de Roma: L. Cornelio Léntulo y C. Claudio Marcelo.

Las posteriores acuñaciones, tanto africanas: RRC 459 (47-46 a.C.), RRC 460 (47-46 a.C.), RRC 461 (47-46 a.C.) y RRC 462 (47-46 a.C.) ${ }^{82}$, como hispánicas: RRC 469 (46-45 a.C.), RRC 470 (46-45 a.C.) y RRC 477 (45-44 a.C.), tampoco mencionan la autoridad del Senado. Ello es debido a que en el momento de efectuarse su fabricación Roma (y, por tanto, el Senado) se encontraban bajo control de César, por lo que es comprensible su silencio $^{83}$. Sea como fuere, la afirmación de Crawford de que las emisiones de Sila y los silanos durante la primera guerra civil, de César y sus oponentes y de los Triunviros y sus contemporáneos eran todas ilegales ${ }^{84}$, no ha de caer en saco roto.

\section{BIBLIOGRAFÍA}

ALFOLDI, A. (1956): “The Main Aspects of Political Propaganda of the Coinage of the Roman Republic". En Essays in Roman Coinage presented to Harold Mattingly (Oxford), 63-95.

ALFöLDI, A. (1966): “Commandants de la flotte romaine stationné à Cyréne sous Pompée, César et Octavien». En Mélanges d'archéologie, d'épigraphie et d'histoire offerts à Jérôme Carcopine (Paris), 25-43.

ALTERI, G. (1990): Tipologia delle monete della repubblica di Roma (con particolare referimento al denario. Città del Vaticano.

AMELA VALVERDE, L. (1990-1991): "La amonedación pompeyana en Hispania. Su utilización como medio propagandístico y como reflejo de la clientela de la gens Pompeia". Faventia 12-13, 181-197.

79 AMELA, 1990-1991, 183; 1999, 23.

80 Causa, quizás, que pudiera explicar en parte la escasez de este tipo de monedas.

81 CRAWFORD, 1974, 461-462.

82 CrawFord, 1974, 471-473.

83 La imposibilidad creciente por parte del Estado de aprovisionar el numerario suficiente para la soldada, acantonadas las legiones en lugares cada vez más alejados de Roma, y las necesidades mayores de la expansión imperialista, crean nuevas condiciones hacen que los imperatores en campaña reciban el derecho de acuñar moneda en cecas móviles (monetae castrenses) o utilizar los talleres monetarics existentes en la provincia, lo que conlleva a que los imperatores o sus subalternos pongan en las monedas tipos propios, aunque la autoridad del Estado se hace constar por el letrero epigráfico EX S.C. o S.C., demostración a los ciudadanos de la legalidad de la emisión.

84 CRAWFORD, 1974, 604. 
Amela VALVERDE, L. (1999): "Acuñaciones de denarios romano-republicanos de Pompeyo Magno en Hispania durante el año 49 a.C.” GN 134, 15-23.

Amela Valverde, L. (2003): Cneo Pompeyo Magno. El defensor de la República romana. Madrid.

ARÉVALO, A. Y CAMPO, M. (1998): "Las emisiones romanas y sus imitaciones en Hispania durante la República». En Historia monetaria de Hispania antigua (Madrid), 318-334.

BABELON, E. (1886): Description Historique et Chronologique des Monnaies de la République Romaine vulgairement appelés monnaies consulaires. Paris.

BANTI, A. Y SIMONETTI, L. (1972): Corpus Nummorum Romanorum. Vol. I. Da Cneo Pompeo a Marco Antonio. Firenze.

BaftulI, C.; Botré, C. Y FABrizI, E. (1997): “Analisi mediante fluorescenza con Raggi $X$ di moneta argentee romane di periodo reppublicano: un'interpretazione storica». RIN 98, 85-107.

Battengerg, CH. (1980): Pompeius und Caesar: Persönlichkeit und Programm in ihrer Münzpropaganda. Diss. Marburg.

Belloni, G. G. (1960): Le Monete Romane dell'Età Repubblicana. Catalogo delle raccolte numismatiche. Milano.

BERnAREgGI, E. (1963): Eventi e personaggi sul denari della Repubblica romana. Milano.

BRoughton, T. R. S. (1952): The Magistrates of the Roman Republic. Volume II. 99 B.C.-31 B.C. Atlanta.

Brougthon, T. R. S. (1986): The Magistrates of the Roman Republic. Volume III. Supplement. New York.

BurnetT, A., AmandRy, M. Y Ripólles, P. P. (1992): Roman Provincial Coinage. Volume I. From the death of Caesar to the death of Vitellius (44 B.C.-A.D. 69). Part I: Introduction and Catalogue. Paris.

Bupzio, H. F. (1961): La marina en la moneda romana. Buenos Aires.

CALDWELL, W. E. (1953): "An Estimate of Pompey". En Studies presented to David Moore Robinson on his seventieth birthday, II (Saint Louis), 954-961.

CAMPO, M. (1973): "Los denarios romano-republicanos acuñados en Hispania". ANum 3, 53-64.

Carson, R. A. G. (1978): Principal Coins of the Romans. Volume I. The Republic c. 290-31 B.C. London.

CatalL, F. (2001): Monetazione romana republicana. Milano.

Chaves Tristán, F. (2001): "El lugar de las cecas en la Hispania romana». En I Luoghi della moneta. Le sedi delle zecche dall'antichità all'età moderna (Milano), 199-218.

COHEN, H. (1857): Description général des monnaies de la Republique Romana communément appelées médailles consulaires. Paris.

Cohen, H. (1930): Description Historique des Monnaies frappées sous l'Empire Romain communèment appelées médailles impériales. Tome premier. Leipzig.

Colbert de Beaulieu, J.-B. (1977): Traité de numismatique celtique, II. La Gaule Belgique. Paris.

Crawford, M. H. (1974): Roman Republic Coinage, 2 vols. Cambridge.

CRAWFORD, M. H. (1982): La república romana. Madrid.

Crawford, M. H. (1985): Coinage and Money under the Roman Republic. Italy and the Mediterranean Economy. London.

FABRICOTTI, E. (1968): “Numa Pompilio e tre monetieri di età republicana”. AlIN 15, 31-38.

Fernández Molina, J.; Fernandez Cabrera, J. y Calico Estivell, X. (2002): Catálogo monográfico de los denarios de la república romana (incluyendo Augusto). Barcelona.

Foss, C. (1990): Roman Historical Coins. London.

Garcia-Bellido, M. P. y Blazouez, C. (2002A): Diccionario de cecas y pueblos hispánicos con una introducción a la numismática antigua de la península ibérica. Volumen I: Introducción. Madrid.

Garcia-Bellido, M. P. y BlAzquez, C. (2002B): Diccionario de cecas y pueblos hispánicos con una introducción a la numismática antigua de la península ibérica. Volumen II: Catálogo de cecas y pueblos. Madrid.

GIL FARRES, O. (1966): La moneda hispánica en la edad antigua. Madrid.

Grueber, H. A. (1910): Coins of the Roman Republic in the British Museum. Vol. Il. Coinages of Rome (continued), Roman Campania, Italy, The Social War, and the Provinces. London.

HARL, K. W. (1996): Coinage in the Roman Economy, 300 B.C. to A.D. 700. London. HERSH, CH. (1980): «The coinage of Quintus Labienus Parthicus». RSN 59, 41-49. 
HIDALGO DE LA VEGA, J. M. (1986-1987): "Uso y abuso de la normativa constitucional en la República tardia: el senatus consultum ultimum y los imperia extra ordinem". SHHA 4-5, 79-99.

HowgEgo, CH. (1995): Ancient History From Coins. London.

KINNs, PH. (1987): "Asia Minor". En The Coinage of the Roman World in the Late Republic (Oxford), 105-119.

KLOSE, D. O. A. (1998): “Zur Chronologie der thessalischen Koinonprägungen im 2. und 1. Jhdt. v. Chr.: Ein weitere Schatund aus Südthessalien». En Stephanos nomismatikos. Edith SchönertGei $\beta$ zum 65. Geburtstag (Berlin, 1998), 333-350.

JONES, A. H. M. (1951): “The Imperium of Augustus". JRS 41, 112-119.

LEACH, J. (1978): Pompey the Great. London.

MARTINI, R. (1996): Sylloge Nummorum Romanorum. Italia. Milano. Civiche Raccolte Numismatiche Res Publica Parte IV - Cra. 345-479/1 (nn. 2142-3310). Milano.

MATTINGLY, H. B. (1963): «Notes on the Late republican Coinage». NC 3, 51-54.

MATTINGLY, H. B. (1977): "Coinage and the Roman State". NC 137, 199-215.

Michel, D. (1967): Alexander als Vorbild für Pompeius, Caesar und Marcus Antonius. Archäologische Untersuchungen. Bruxelles.

MILLAN, C. (1965): «Aspectos hispánicos de la familia Pompeia». En Congresso internazionale di Numismatica. Atti, II (Roma), 293-298.

Momigliano, A. (1942): “Terra marique». JRS 32, 53-64.

MuÑIz CoelLo, J. (1982): El sistema fiscal en la España romana (República y Alto Imperio). Zaragoza.

Perez, CH. (1986): Monnaie du pouvoir. Pouvoir de la monnaie. Une pratique discursive originale: le discours figuratif monétaire (1er s. av. J.-C.-14 ap. J.-C.). Besançon.

Perez, Ch. (1989): La monnaie de Rome a la fin de la Republique. Un discours en images. Paris.

PICARD, O. y GJONGeCAI, SPH. (2000): “Les drachmes d’Apollonia à la vache allaitant». RN 155 (2000), 137-160.

Rolland, H. (S.D.): Numismatique de la République Romaine. Catalogue General et raisonée. Paris.

Saez Balaño, J. A. y Blanco Villero, J. M. (1996): Las monedas de la Bética romana. Vol. I. Conventus Gaditanus. San Fernando.

Sauron, G. (1995): Qvis Devm? L'expression plastique des idéologies politiques et religieuses à Rome à la fin de la République et au début du Principat. Rome.

SCHEERS, S. (1969): Les monnaies de la Gaule inspirées de celles de la République romaine. Paris.

SCHEERS, S. (1976): “L'histoire monétaire de la Gaule Belgique après la conquête de César». En Actes du $8^{\mathrm{ems}}$ Congrès International de Numismatique (Paris), 197-201.

SCHEERS, S. (1977): Traité de numismatique celtique, Il. La Gaule Belgique. Paris.

Sezby, H. A. (1967): Roman Silver Coins Vol. I. The Republic to Augustus. London.

SEAR, R. S. (1998): The History and Coinage of Roman Imperators, 49-27 BC. London.

STANNARD, C. (1995): "Two-headed and two-tailed denarii again". AN 17, 361-362.

StEVENSON, S. W. (1964): A Dictionary of Roman Coins, Republican and Imperial. London.

SUTHERLAND, C. H. V. (1974): Monnaies romaines, Fribourg.

SYME, R. (1960): «Piso Frugi and Crassus Frugi». JRS 50, 12-20.

SYME, R. (1989): La revolución romana. Madrid.

SYDENHAM, E. A. (1952): The Coinage of the Roman Republic. London.

VILLARONGA, L. (1987): Numismática antigua de Hispania. Iniciación a su estudio. Barcelona.

WALKER, D. R. (1980): «The Silver Contents of the Roman Republican Coinage". En Metallurgy in Numismatics, I (London), 55-72.

WALLACE-HADRILL, A. (1986): “The emergence of the imperial coinage». JRS 76, 74-87.

WISEMAN, T. P. (1974): “Legendary Genealogies in Late-Republican Rome», G\&R 21, 153-164.

ZEHNACKER, H. (19738): Moneta. Recherches sur l'organisation et l'art des émissions monétaires de la République romaine (289-31 av. J.-C.). 2 vols. Rome. 